\title{
A revolução será memetizada: engajamento e ação coletiva nos memes dos debates eleitorais em $2014^{1}$
}

\section{João Guilherme Bastos Santos e Viktor Chagas}

\section{Resumo}

0 presente artigo tem como proposta desenvolver uma reflexão sobre a relação entre engajamento político, conversação informal e ação coletiva através da brincadeira política (political play). 0 objetivo é compreender um tipo particular de informação política que circula nas mídias sociais, os memes de internet. Dando sequência a uma agenda de investigações mais ampla, este trabalho pretende analisar um conjunto de 73 imagens pertencentes a uma amostra original de 599 memes coletados durante 0 debate eleitoral transmitido pela Band, em 2014. Em comum, todas essas imagens foram publicadas no Twitter e apresentam fotografias de uma televisão que exibia o debate. Interessa-nos perceber em que medida é possível (1) qualificar essas imagens como meme político, (2) caracterizá-las como uma ação coletiva baseada na conversação informal, e (3) identificar qual é o posicionamento político predominante expresso por elas. Para dar conta dessas questões, empreendemos uma análise de conteúdo conjugada a uma avaliação qualitativa desses materiais. Os resultados apontam para a necessidade de repensarmos a conexão entre engajamento cívico e ação política a partir da perspectiva do envolvimento casual do cidadão médio com a política na internet.

\section{Palavras-Chave}

Memes. Internet e política. Eleições 2014. Engajamento.

\section{João Guilherme Bastos Santos}

gui_bsantos@hotmail.com

Doutorando do Programa de Pós-Graduação em Comunicação da Universidade do Estado do Rio de Janeiro - UERJ, Brasil.

Viktor Chagas I viktor@midia.uff.br

Doutor em História, Política e Bens Culturais pela Fundação Getúlio Vargas - FGV, Brasil. Professor do Departamento de Estudos Culturais e Mídia e do Programa de Pós-Graduação em Comunicação da Universidade Federal Fluminense - UFF, Brasil.

\section{Introdução}

Estudos recentes dedicados às intersecções entre comunicação e política têm se debruçado sobre as maneiras pelas quais os indivíduos se engajam em determinadas mobilizações, tendo assumido de modo unívoco a preocupação em apontar modelos que busquem explicar o processo através de sua natureza sequencial, isto é, com ações tomadas de forma pioneira por indivíduos que desencadeiam outras ações subsequentes (id., ibid.; MARGETTS et al., 2013). Apesar disso, as análises convergem para uma leitura de que, embora seja absolutamente relevante avaliar 0 desencadeamento destas ações em larga escala, a chave do engajamento ajuda apenas em parte a explicar suas causalidades. É nessa linha que Bimber, Flanagin \& Stohl (2012) investem, na tentativa de conciliar as teorias da ação coletiva e das organizações. 0s autores dispõem as novas formas de organização coletiva a partir de dois eixos, engajamento e interação pessoal. Mas, no afã de investigar as razões por que os indivíduos se engajam em determinadas ações coletivas, e como este engajamento opera no cenário do atual desenvolvimento das tecnologias da informação 
e da comunicação, os pesquisadores deixam de

lado o questionamento sobre $o$ que é efetivamente uma ação engajada. 0 presente trabalho procura ocupar esta brecha nos estudos sobre comunicação política e ação coletiva.

Para propor esta discussão, nos ancoramos em etapa anterior de pesquisa (CHAGAS et al., 2017), sobre a qual investigaram-se memes políticos que circularam durante os debates eleitorais entre candidatos à Presidência apresentados pelas principais emissoras de televisão do Brasil em 2014; e em estudos que apontam como a troca de razões formais tem um papel, muitas vezes, secundário frente a dimensão relacional, motivações fundeadas por identificações culturais e pelo prestígio dos atores que compartilham informações e campanhas ampliando exponencialmente seu raio de alcance (ALDÉ \& SANTOS, 2012). A união dessas duas propostas nos conduz a uma perspectiva menos centrada em aspectos formais institucionais e mais interessada em proposta de pesquisa que entenda o papel do aspecto lúdico de uma cultura política na circulação de informação e engajamento pelo "cidadão comum", buscando contribuições do conceito de brincadeira política (BENNETT, 1979) para compreensão dos memes compartilhados durante a eleição presidencial de 2014.

Em investigação anterior sobre memes políticos, tratando de amostra preliminar de pesquisa, foi analisado 0 conteúdo de cerca de 600 imagens $^{2}$ publicadas no Twitter durante e até 48h após o debate presidencial exibido pela emissora Bandeirantes no dia 26 de agosto de 2014. A intenção era propor uma taxonomia para os memes políticos, conjugando trabalhos recentes na área (SHIFMAN, 2014; TAY, 2012; BENNETT \& SEGERBERG, 2012, e outros) a estudos sobre propaganda eleitoral e estratégia retórica no HGPE (Horário Gratuito de Propaganda Eleitoral) produzidos por pesquisadores brasileiros na década de 1990 (FIGUEIRED0 et al., 1998). 0 resultado apontou para um exercício interessante de diálogo entre categorias analíticas já consolidadas na comunicação política e uma matriz desdobrada a partir dos estudos de memes propostos por Shifman (2014), a qual distingue os conteúdos políticos gerados por usuários em memes persuasivos, memes de ação popular e memes de discussão pública.

Uma versão anterior deste trabalho foi apresentada no XIV Congresso Brasileiro de Comunicação e Marketing Político (Politicom), no GT Imagem, Opinião Pública e Democracia, realizado na Universidade Federal do Estado do Rio de Janeiro (Unirio), Rio de Janeiro, nos dias 2 e 3 de setembro de 2015. A presente versão revisa e corrige pequenos detalhes. Agradecemos aos colegas do GT pelos comentários. Agradecemos também nominalmente aos colegas Alessandra Aldé, Fernando Lattman-Weltman, Luciana Fernandes Veiga e Rosane Manhães Prado pela leitura e crítica de trabalhos anteriores, que nos motivaram a produzir o presente artigo. Por fim, mas não menos importante, agradecemos aos avaliadores cegos deste periódico que enriqueceram a análise com seus pareceres.

0 total de conteúdos coletados durante os cinco debates no primeiro turno e os quatro debates no segundo turno foi de aproximadamente 6 mil imagens. 
Com base nesta categorização inicial, aprofundada por Chagas et al. (2017), e seguindo na esteira do trabalho de Bennett \& Segerberg (2012), que desenvolve a noção de ação conectiva - em oposição às ações coletivas tradicionais, capitaneadas por organizações formais como partidos, associações sindicais, etc. -, identificamos como memes de ação popular "aqueles que se caracterizam por uma construção coletiva de sentido", buscando mobilizar 0 cidadão comum, e frequentemente apontando para comportamentos coletivos reiterados, como selfies e outras tendências (CHAGAS et $a l .$, 2017). A matriz de Bennett \& Segerberg (2012) propõe três tipos de ação organizada: as ações coletivas tradicionais, as ações coletivas híbridas e as ações conectivas, criando uma espécie de escala que procura determinar 0 grau de centralização na organização desses movimentos simultaneamente em relação ao papel desempenhado pelas tecnologias da comunicação. Esta tipologia, no entanto, não foi suficiente para darmos conta de um fenômeno que, reiteradamente, se apresentava em meio ao material analisado no corpus inicial desta pesquisa: fotografias de aparelhos televisores que exibiam o debate em tempo real, em geral obtidas pelo próprio autor do post, em ambiente domiciliar. As fotos, muitas vezes surgindo desacompanhadas de comentários, apresentavam um aposento em que a televisão centralizava as atenções, e, nela, o debate presidencial se desenrolava. Em muitos casos, não havia justificativa nem explicação para a imagem publicada, ou sequer uma explanação favorável ou contrária a determinado candidato. Apenas a televisão transmitindo o debate, de tal modo que não conseguimos supor se aquela se tratava ou não de uma ação engajada, o que nos inquietou e nos levou a um novo problema de pesquisa.

A quantidade expressiva deste tipo de conteúdo nos obrigou a criar uma categoria própria que nos permitisse enquadrá-lo, a que denominamos, por ausência de melhor designação, "dinâmica de ação conectiva de engajamento relativo". Essa categoria se somou às três outras já esboçadas por Bennett \& Segerberg (2012), de maneira a nos permitir avaliar o grau de engajamento suposto por esses memes de ação popular (SHIFMAN, 2014).

0 artigo que ora apresentamos está endereçado a responder às questões advindas desta descoberta inicial de um corpus dentro de nosso corpus. Concentrando-nos na amostra de 73 imagens - 0 que equivale a $12,2 \%$ do corpus inicial de 599 imagens analisadas em trabalho anterior -, as quais apresentam uma peculiaridade marcante: todas decorrem de usuários que fotografaram suas próprias televisões durante 0 debate -, pretendemos discutir os limites teóricos da dimensão do engajamento em face às ações coletivas empreendidas a partir das mídias sociais. Em paralelo, procuramos debater, em vista desta questão, quais são as fronteiras epistemológicas do conceito de meme político, e como podemos aplicá-lo às imagens que ora constituem nossa base empírica. Por fim, procuraremos identificar 
padrões de linguagem e conteúdo a partir da análise desses memes, e responder qual 0 significado político de imagens como as dispostas no Quadro 1.

Não é nosso escopo, no presente momento, investigar se e quem são os sujeitos mais influentes na criação e espalhamento de memes e nem quais os efeitos políticos dos memes no universo das campanhas eleitorais. Reconhecemos a existência de uma literatura endereçada à compreensão das mudanças no panorama das campanhas online e na utilização política da comunicação digital (STROMER-GALLEY, 2013; AGGIO, 2015; CERVI, MASSUCHIN \& CARVALHO, 2016), bem como de um conjunto recente de pesquisas que enfatizam o papel do Twitter como plataforma de conversação sobre a política (GAINOUS \& WAGNER, 2014; AGGIO, 2015; e outros). 0 corrente estudo, entretanto, se dirige a interpretar um fenômeno comportamental específico, traduzido como expressão de engajamento casual na discussão política.

Para alcançarmos esses objetivos, estruturamos este artigo em três capítulos. No primeiro deles, discutiremos como a literatura tem tratado, sob prisma teórico, as ações coletivas organizadas no contexto de mudança tecnológica. Em seguida, intentamos aprofundar a interface entre os estudos de internet - notadamente, as análises sobre o fenômeno dos memes - e a abordagem das culturas políticas, de modo a buscar uma definição mais precisa para o engajamento político e 0 significado da ação engajada. Por último, partimos para uma análise de conteúdo sobre as imagens coletadas, com o propósito de investigar padrões de apresentação e motivações para 0 compartilhamento desses conteúdos.

Assim, a pesquisa que empreendemos busca encontrar respostas para as seguintes questões, a serem repercutidas nos próximos capítulos deste artigo:

(Q1) De que maneira é possível qualificar as imagens com fotos de aparelhos de televisão exibindo 0 debate eleitoral como um tipo de meme político?

(Q2) Em que medida as imagens com fotos de aparelhos de televisão exibindo o debate eleitoral traduzem um tipo de ação coletiva baseado na conversação informal na internet?

(Q3) Em caso positivo, qual é o posicionamento político predominante expresso pelos sujeitos que publicam este tipo de material?

\section{DNA da ação coletiva}

\section{A simplificação de obstáculos para interação e} articulação de ações coletivas independentes de organizações e instituições, decorrente de modos de apropriação diversos, adiciona novas questões aos estudos sobre ações individuais, apropriações e comunicação política. Para compreendê-las, tomaremos como referência introdutória os estudos de Bruce Bimber, Andrew Flanagin \& Cynthia Stohl (2012). Tais estudos apontam o fato de que os principais obstáculos para a realização de objetivos coletivos - como o agrupamento de 
uma massa crítica com objetivos compartilhados e a viabilização de formas de colaboração difusas têm sido consideravelmente simplificados através da difusão de suportes para redes sociais virtuais e suas modalidades de integração independentes de organizações centralizadas (BIMBER, FLANAGIN \& STOHL, 2012; SANGLARD \& SANTOS, 2013).

As possibilidades e capacitações decorrentes do desenvolvimento de mídias sociais trazem duas inovações importantes para a compreensão da ação coletiva na contemporaneidade: a maneira como a apropriação destas tecnologias promove, mesmo que nem todos os membros envolvidos nas ações em questão tenham acesso a essas tecnologias, uma espécie de ubiquidade $d a$ infraestrutura sociotécnica; e a estrutura tecnológica que facilita o envolvimento entre as pessoas em âmbito social, político e intelectual ${ }^{3}$. Entretanto, a ideia de que o conteúdo político que circula na internet determina efeitos homogêneos sobre a população em geral ignora as diferenças entre a repercussão deste conteúdo entre pessoas interessadas ou engajadas em temas políticos - jornalistas, pesquisadores, militantes, etc. - com maior envolvimento e consumo intenso de informações políticas, e a repercussão desses temas entre a maioria esmagadora dos cidadãos comuns. Entre os indivíduos engajados, a aproximação de pessoas com posições políticas similares e que, anteriormente, poderiam estar isolados uns dos outros pode ser mais propensa ao reforço de preconceitos e da reelaboração da distinção política básica entre "amigos" e "inimigos", que marca os efeitos de polarização e radicalização (LATMAN-WELTTMAN, 2015). Essa discussão retoma a questão das consequências de redes "ego-centradas", de acordo com as escolhas pessoais sobre com quem e quando discutir temas políticos para o posicionamento e participação política das pessoas que fazem estas escolhas (KNOKE, 1990). A queda da exposição ao desacordo político tem relação, nesta discussão, com o princípio de homofilia

A ideia de ubiquidade da infraestrutura sociotécnica pode ser demonstrada por meio de dois exemplos interessantes. Primeiro, a importância do automóvel na sociedade norte-americana faz com que boa parte da configuração espacial e arquitetônica da cidade busque explorar as potencialidades econômicas e sociais do uso desta nova tecnologia, o que faz com que o impacto da "cultura do automóvel" no planejamento urbano e na prática social seja palpável, mesmo se a maioria das pessoas presentes naquele ambiente não tiver um carro. A interação cada vez mais intensa entre redes sociais e a mobilização política para ação coletiva compõe um cenário onde mesmo aqueles que não participam deste tipo de apropriação tecnológica das redes sociais se deparam, direta ou indiretamente, com seus efeitos em diversos âmbitos de interação social (BIMBER, FLANAGIN \& STOHL, 2012). 0 segundo exemplo nos auxilia ao tornar clara uma ressalva importante. Em cada etapa da popularização do telefone fixo, mais pessoas foram incluídas como usuários, novos usos e conexões sociais foram explorados, novas expectativas e possibilidades sociais envolvidas. 0 telefone se tornou tecnologia básica para o funcionamento social e político, portanto, uma infraestrutura ubíqua, alterando a forma como as pessoas pensam em organizar os esforços coletivos e a percepção dos custos envolvidos na mobilização política. Contudo, não se espera que haja correlação direta entre utilização pessoal do telefone e aumento do engajamento cívico, ou maior atuação política por parte dos cidadãos que 0 utilizam mais intensamente. 0 reconhecimento da possibilidade de apropriações políticas inovadoras não determina a ocorrência desta apropriação (BIMBER, FLANAGIN \& STOHL, 2012). 
(KNOKE, 1999, p. 1043), ou seja, a tendência de pessoas a escolherem outras pessoas com características semelhantes para discutir esses temas, reforçando posições preexistentes, caso as encontre em grande número.

A relativização dos diagnósticos sobre a polarização generalizada ou sobre os efeitos do acesso à internet ganha relevo em pesquisas da área críticas a afirmações sobre a atuação política do cidadão conectado, como se todo e qualquer cidadão com acesso à internet tivesse o mesmo comportamento, que desconsideram as diferentes apropriações políticas, segmentações e perfis de consumo de informações envolvidas na relação do cidadão médio com essas tecnologias.

Partindo desta postura crítica, empenhada no cruzamento entre 0 interesse político dos cidadãos comuns - diferenciando-os dos engajados - e as influências de tecnologias e veículos de comunicação sobre seu comportamento, bem como suas opções com relação a apropriações possíveis destas últimas, este tema recebe particular atenção nos trabalhos de Aldé (2004; 2011a; 2011b). Seu foco está na relação de diferentes combinações entre hábitos de consumo de mídia do "cidadão comum", percepções em relação ao ambiente político e intensidade de interesse por parte do cidadão médio.

As pesquisas sobre debates na internet, e a necessária exposição ao desacordo político implicada nestes, têm mostrado um caráter aparentemente paradoxal: se, por um lado, a busca por informações está associada à chamada "exposição seletiva", a qual contribui para uma redução no acesso a informações contrárias a posições políticas dos usuários que buscam informações na rede, por outro, 0 enfraquecimento de "fronteiras sociais" aumenta a oportunidade para exposiçãa inesperada ao desacordo político (BRUNDIDGE \& RICE, 2010). Considerando a circulação social dos memes, é fácil entender sua relevância para a presente proposta de estudo: sua capacidade de permear diversas esferas, de militantes a leigos, com um forte componente relacional, ao mesmo tempo em que traz pautas políticas, dialoga diretamente com este paradoxo.

Um ponto fundamental a ser levado em consideração é o fato de que as tecnologias, por conta própria, não organizam os laços que compõem os sites de redes sociais separadamente das histórias que as pessoas compartilham através destas tecnologias (BENNETT \& TOFT, 2010, p. 247). Este é um ponto importante para a compreensão de estratégias que revitalizam ferramentas como petições públicas, frequentemente apropriadas por organizações civis transnacionais em defesa de direitos humanos e do meio ambiente.

Bennett \& Toft (2010, p. 249-251) diferenciam narrativas pessoais e específicas de enquadramentos (frames) mais amplos e que 
dão sentido a uma dada campanha ${ }^{4}$. Nesta linha de raciocínio, propõem entender "narrativas" como uma condicionante da rede, que participa na construção de laços sociais e provê contextos interpretativos para os "enquadramentos" das campanhas, fazendo com que diferentes redes pessoais possam ser associadas a uma rede mais ampla de suporte, e inspirando então a ação coletiva. Segundo Bennett \& Segerberg (2012, p. 746), é possível também encontrarmos proximidade entre a noção de enquadramento e 0 conceito de meme, na medida em que este se constitui como um slogan de "ricas histórias de transmissão social”’ .

Entre os dois trabalhos citados anteriormente, que têm Bennett como autor em comum, há uma diferença em relação à percepção sobre ação coletiva. 0 artigo conjunto com Segerberg, publicado em 2012, propõe uma distinção entre a ação coletiva e ação conectiva, que ainda não estava presente no trabalho anterior com Toft, publicado em 2010. Em resumo, a safra mais recente estabelece uma diferença entre a ação coletiva fundamentada na lógica da escolha racional que envolve 0 bem público, e a ação coletiva (ou conectiva, como batizam os autores) baseada na negociação de enquadramentos e identidades. Esta última leva em consideração as relações e os laços afetivos envolvidos na tomada de decisão ante a ação política. Diferentemente da ação coletiva tradicional, a ação conectiva constituiria uma digitally networked action (DNA), marcada por altos níveis de personalização na apropriação de frames e sua circulação na rede.

Embora os autores citados tenham filiações teóricas e focos de pesquisa diversos, alguns pontos perpassam seus trabalhos, como, por exemplo, a relação entre infraestrutura sociotécnica e ação política, seja na percepção de ações executadas sem organizações (BIMBER, FLANAGIN \& STOHL, 2012) ou de uma liderança sem líderes (MARGETTS et al., 2013). Em todos os casos, observa-se a constituição de redes de ação política - as quais não estão determinadas pela simples possibilidade tecnológica - através das opções pessoais de cada um dos implicados. Ao mesmo tempo em que a consideração das redes envolvidas com ação política transcende o foco no indivíduo

Utilizamos o termo campanha aqui para nos referirmos a contextos de ação política disputada, em acepção próxima à de campanhas eleitorais, mas também à de campanhas em mídias sociais, como as desempenhadas por redes de mobilização como Avaaz, Move0n e Petição Pública.

Bennett \& Segerberg (2012, p. 746) exemplificam sua comparação com o slogan “Eat the Rich" (“Coma os ricos”), entoado em manifestações contra as políticas do G-20 em Londres: "Esta frase icônica particular pode ser datada a partir do sofisma de Rousseau: 'Quando as pessoas não tiverem mais nada para comer, elas comerão os ricos'. 0 curioso curso deste meme através dos anos inclui sua aparição em camisetas nos anos 1960 e em canções de rock de bandas como Aerosmith e Motorhead, apenas para arranhar a superfície de sua viagem histórica pelo tempo e espaço, refletindo em uma sequência de apropriações, expressão pessoal e compartilhamento". 
como unidade isolada, a importância crescente atribuída às opções pessoais em manifestações em mídias sociais teria trazido um elemento narcisista à intervenção na rede (PAPACHARISSI, 2010) e conferido nova relevância a traços de personalidade e afinidades pessoais (MARGETTS et al., 2013).

Neste cenário de personalização e apropriação tecnológica, considerando propostas que diferenciam apropriações de uma mesma tecnologia segundo diferentes manifestações - diferenciando as experiências de assistir a um jogo pela televisão em família, em um telão de um bar de esportes, no telão de um estádio, etc. -, segundo diferentes usos, uma vez que aparelhos de televisão semelhantes podem ser utilizados tanto para assistir canais de TV aberta quanto TV a cabo, ou assistir vídeos gravados, jogar videogame, navegar na internet (GROSSBERG et al., 2006, p.8-10), como podemos interpretar o fato de um número considerável de memes da eleição presidencial de 2014 envolverem fotos de televisões que passavam o debate presidencial, a maioria em ambiente doméstico? Nos parágrafos a seguir, procuramos discutir como esse panorama se relaciona com uma eventual percepção lúdica sobre 0 universo da política.

\section{Brincadeira política como 'serious business'}

Em artigo de 1979 - portanto, bastante anterior ao cenário contemporâneo dos memes de internet -, W. Lance Bennett explorava as relações entre 0 arcabouço teórico da Comunicação Política e da chamada Play Theory. No texto, Bennett (1979, p. 344), que mais tarde viria a trabalhar com Alexandra Segerberg para redefinir a noção de ação coletiva diante do panorama das novas mídias, argumentava que a brincadeira política ${ }^{6}$ pode se tornar um agente de mudanças sociais, orientando novos arranjos institucionais em contextos de turbulência política. 0 conceito de brincadeira política a que Bennett alude introduz 0 aspecto lúdico ao tratamento do teatro político (cf. GOMES, 2004), e conecta a abordagem da teoria da ação coletiva a um olhar mais centrado nas culturas políticas do que em seu viés institucional ou formal. Bennett (op. cit.) explica que o conceito de brincadeira, oriundo dos estudos de pedagogia e psicologia social, pressupõe estados de transformação, controle e afirmação pessoal. Nesta acepção, um objeto é transformado em sua essência emocional ou intelectual, constituindo-se como alegoria ou metáfora-viva, sob controle do jogador/ator político. "Quando os objetos de brincadeira estão sob controle de um player, a brincadeira se 
converte em um meio de satisfazer sua própria expressão pessoal" (BENNETT, 1979, p. 333).

Em um dos exemplos do autor, para demonstrar como estas três condições são operadas, ele cita protestos contra a Guerra do Vietnã em que ativistas colocaram flores nos canos dos rifles de policiais?

0s memes obedecem a essas mesmas condições, basta ter como exemplo os "diálogos" ficcionais desenvolvidos por espectadores dos debates eleitorais - e publicados em conjunto com suas fotos da televisão. Como Bennett \& Segerberg (2012, p. 747) lembrariam, os enquadramentos de ações coletivas que apresentam queixas políticas comuns podem muito bem ser compreendidos como memes. Essas narrativas ritualizadas e recontextualizadas viajam através das redes sociais, dizem os autores (id., ibid.), buscando, nem sempre com sucesso, transpor barreiras estabelecidas por organizações políticas tradicionais, com suas ideologias, seus interesses, e demais clivagens sociais e subculturais.

Em contraste com a aposta dos autores no poder do capital social para disseminar essas demandas, Bimber, Flanagin \& Stohl (2012, p. 90) afirmam que modelos de organização transnacionais contemporâneos, como o Move0n, têm apostado em dinâmicas de interação impessoal, em que importa mais o quantitativo de indivíduos que expressam uma posição em comum.

Seguindo este raciocínio, os pesquisadores definirão engajamento político como o "grau em que indivíduos participam dos processos de constituição da agenda organizacional e de tomada de decisão" (id., p. 92). E Dahlgren, citado por Milner (2013, p. 2372), se referirá ao engajamento como uma pré-condição para a participação política. Stromer-Galley (2013) diferenciará interação de participação, para deixar claro que o regime democrático, seja ele calcado na participação popular ou na institucionalidade da representação, se funda sobre a interação em vista do processo de tomada de decisão.

Linda Börzsei (2013, p. 18-19), ao pesquisar memes políticos húngaros, chega à conclusão de que a principal função da cultura política, especialmente através da cultura popular da internet, é familiarizar os indivíduos com a linguagem política e criar espaços comuns de demanda e opinião. As tecnologias da comunicação, notadamente a internet, diz a pesquisadora, têm criado novos modos de participação em que os sujeitos desenvolvem sua orientação política a partir desses processos interativos. Como efeito, por vezes, temos "amadores políticos" sendo convertidos em experts. Mas a popularização da participação política tem, no mínimo, dois lados. Conforme Bennett (1979, p. 346), a brincadeira incorpora 
um dispositivo que permite que mesmo as imagens eleitorais mais "bizarras" sejam compreendidas como metáforas dentro da rotina de campanha. $\mathrm{E}$, assim, este "conjunto de oportunidades para imitar e improvisar o cenário político", ao invés de se caracterizar como elemento alienante, se transforma em expressão coletiva de criatividade (id., p. 342), para a qual é preciso dispender energia, já que consiste em uma nova experiência de letramento político.

Esta energia, descrita por Margetts et al. (2013, p. 1) como fonte inclusive para mobilizações em larga escala, se apresenta na forma de "'microdoações' de recursos", iniciativas individuais ritualizadas como ação coletiva. Os memes políticos materializam o olhar sobre a brincadeira através das novas mídias e diluem as fronteiras entre 0 que pode e 0 que não pode ser considerado ação engajada. Afinal, se 0 engajamento pode ser compreendido como uma tentativa de tomar parte do processo de constituição da agenda pública, como descrevem Bimber, Flanagin \& Stohl (op. cit.), acompanhar os debates televisivos, fotografando a própria televisão, e emitindo (ou não) comentários sobre a performance dos candidatos, mesmo quando investidos de ficção ou fantasia, é um "comportamento social" com "ação direta no mundo físico" (BENNETT, 1979, p. 335), uma das características mais marcantes da brincadeira política. 0 exercício que desempenhamos a seguir tenta dar conta de uma reflexão sobre a gramática dessas imagens.

\section{Metodologia}

A presente investigação se ancora em metodologia própria do grupo de pesquisa coLAB/UFF, desenvolvida inicialmente por Chagas et al. (2017) e tecnicamente detalhada por Chagas \& Toth (2016). Trata-se de uma análise de conteúdo direcionada, investida de categorias previamente definidas e especificadas em livro de códigos disponível em <http://www. museudememes.com.br/codebook $>$. $0 \mathrm{~s}$ materiais analisados são imagens coletadas nas mídias sociais. 0 procedimento de análise é levado a efeito por uma equipe de dois codificadores, gerando dados categóricos posteriormente tratados de forma estatística.

Para esta etapa da pesquisa, foram coletadas, através da hashtag \#DebateNaBand, as imagens que circularam no Twitter entre os dias 26 e 28 de agosto. A operação foi realizada por meio do aplicativo Twicsy e resultou em um total de 599 imagens de memes de internet ${ }^{8}$. 0 Twicsy realiza buscas diretamente na API do Twitter e apresenta uma amostra integral das imagens publicadas na rede a partir das palavras-chave utilizadas na pesquisa, com limite de até 1000 resultados por busca, ordenados do mais recente para o mais 
antigo. No caso em questão, o limite de 599 imagens corresponde ao total de publicações atreladas à hashtag pesquisada nas $48 \mathrm{~h}$ que sucederam ao debate. Dessa amostra inicial, 73 imagens apresentaram uma peculiaridade marcante: todas haviam sido obtidas por usuários que fotografaram suas próprias televisões durante 0 debate.

Consideramos fotografias de televisão enquadrada quando as bordas da televisão ou o ambiente ao seu redor eram representados no enquadramento da imagem, ou quando a resolução da imagem apresentava distorções ou detalhes da varredura de um aparelho televisor. Foram desconsideradas da análise imagens obtidas a partir de frames digitais, compartilhadas nos perfis de mídias sociais da própria emissora de televisão ou de outros veículos profissionais jornalísticos ou de humor que acompanhavam o debate.

Em alguns destes posts, as imagens eram acompanhadas de legendas que funcionavam como dispositivos de ficcionalização, construindo narrativas sobre os acontecimentos reais recontextualizados. Em outros, mais raros, as legendas expressavam algum posicionamento: "Cheguei, meu povo! E já afirmo... \#SAUDADEdoBRIZOLA Minha 'escola' é outra. Kd a paixão?" ou "[Dilma com] Cara de fodeu". Vários eram os casos, no entanto, de legendas anódinas, como "Assistindo [a]o debate com os candidatos para presidente \#Eleições2014" e "kkkkkkkk", ou ainda simplesmente da ausência delas, diante da imagem da televisão enquadrada na fotografia.
A pesquisa buscou ainda combinar uma avaliação qualitativa das imagens, tanto em relação ao conjunto de fotografias com a televisão enquadrada, quanto em relação com o corpus original de 599 imagens. Temos, portanto, como antecipado, um corpus dentro de um outro corpus.

As variáveis através das quais os materiais foram analisados envolvem categorias que dizem respeito à linguagem dos memes (que gêneros de memes são mais frequentes, que elementos são recorrentes nos corpora analisados), à natureza política dos conteúdos (quais candidatos aparecem representados, quais partidos, etc.), e à avaliação da função política exercida por eles (se memes persuasivos, de ação popular ou de discussão pública, conforme Chagas et al., 2017).

Naturalmente, nem todas as imagens coletadas na amostra de 599 arquivos reunidos ao longo do debate na Bandeirantes poderiam ser classificadas stricto sensu como meme. Problematizações a respeito dessa categoria foram inicialmente levantadas em trabalho anterior (CHAGAS et al., 2017), quando aludimos à definição de Shifman (2014) sobre este tipo de conteúdo. Segundo a autora, memes não se constituem - tal como na conceituação original de Dawkins (1976) - meramente como unidades de reprodução cultural, mas como acervos e coleções de "experiência compartilhada" (SHIFMAN, 2014). E, por essa razão, avaliar uma imagem isolada de seu contexto, sem atentar para o conjunto que forma com as demais, é descaracterizar o acervo em si 
mesmo. Nesse sentido, as fotografias de televisão correspondem a um padrão social que não apenas evidencia a tendência à compreensão da internet $\mathrm{e}$ das novas mídias como segunda tela, mas também se destaca como experiência "intertextual" e, acima de tudo, "interdiscursiva" (MILNER, 2013). Assim é que um sem número de jogos e desafios se converte em memes famosos nas mídias sociais, como o Desafio do Balde de Gelo (Ice Bucket Challenge), o Lying Down Game, Put Shoe on Head, Batmanning, entre outros ${ }^{9}$.

Conforme Milner (2013), trata-se de uma condição extratextual. 0 pesquisador alude aos memes surgidos durante a fase de protestos do movimento Occupy Wall Street, especialmente o meme conhecido como "eu sou os 99\%", para explicar que o processo de conformação dos memes extrapola 0 sentido individual de cada peça. No exemplo dado, diversas imagens de selfies em que 0 indivíduo segura uma folha de caderno com uma pequena redação manuscrita, dando conta de histórias de vida ou de dificuldades pessoais e encerrada com o bordão "eu sou os 99\%", que lhes identificava com a massa de protestantes, circularam por redes como Tumblr, Twitter e outras.

Textualmente, elas são independentes entre si, imagens estáticas, livres de comentários ou remixes. Entretanto, extra-textualmente, são dependentes de um processo memético que entrelaça imitação e transformação a partir de uma convenção nuclear comum, uma performance de cidadania associada de modo polivocal às perspectivas de outros cidadãos (MILNER, 2013, p. 2371).

De acordo com o KnowYourMeme, principal base de dados colaborativa sobre memes de internet, os photo fads, uma categoria nativa reconhecida como gênero particular de meme, são "fotos encenadas em que 0 sujeito posa de uma maneira específica, geralmente com a finalidade de compartilhar a imagem nos meios online" ${ }^{10}$. As fotografias de televisão não constituem exatamente um photo fad, na medida em que não há pose encenada por qualquer sujeito, se não aqueles que espontânea e inadvertidamente são fotografados em tempo real a partir da imagem televisionada. Apesar disso, a tendência que se espalhou como "mania" orgânica ${ }^{11}$ nas mídias sociais no Brasil, notadamente no Twitter, diz

Ice Bucket Challenge foi um desafio proposto por alguns usuários de mídias sociais a seus pares, entre eles celebridades e anônimos. 0 objetivo original era doar US\$100 a uma entidade filantrópica dedicada à pesquisa médica sobre os sintomas da Esclerose Lateral Amiotrófica (ELA). Aqueles que não pudessem doar ou preferissem não fazê-lo deveriam filmar-se em vídeo jogando sobre suas cabeças um balde de gelo. Lying Down Game foi um jogo em que os sujeitos se fotografavam deitados de bruços em cenários esdrúxulos. Put Shoe on Head e Batmanning seguiam o mesmo estilo de desafio. No primeiro, os sujeitos deveriam se fotografar com um sapato na cabeça, enquanto, no segundo, as fotos apresentavam uma pessoa dormindo de ponta-cabeça, como um morcego.

10 Disponível em: <http://knowyourmeme.com/memes/subcultures/photo-fads>. Acesso em: 20 de agosto de 2015.

11 Milner (2013, p. 2371) lembra que, ainda que espontâneos, nem todos os memes são orgânicos. Alguns deles, como as imagens com os dizeres "eu sou os 99\%", possuem "regras" de participação cunhadas pela própria comunidade. 
muito sobre o comportamento político desta esfera pública. Vale dizer, como lembra Herrera (2015), os memes podem atuar como "comentários sociais", evidenciando a expressão criativa dos usuários, como espécie de $f a n f i c^{12}$ política construída a muitas mãos e em tempo real.

Com base nesse entendimento teóricoepistemológico e seguindo os procedimentos metodológicos anteriormente apresentados, obtivemos os resultados descritos na sequência.

\section{Discussão}

"vai encarar, Pastor[?] volta pra casa ou vai para o culto[.] isso aí não é a sua praia". A legenda integra parte do conteúdo coletado durante os debates eleitorais em 2014, e se justapõe a uma imagem publicada por um usuário do Twitter que apresenta uma fotografia da própria televisão, com a tela dividida longitudinalmente entre Dilma Rousseff e Pastor Everaldo

(Imagem 1). A imagem é exemplar da prática que se tornou uma tendência na rede a partir do dia 26 de agosto - data em que foi ao ar 0 primeiro debate televisivo do primeiro turno das Eleições 2014 -, a publicação de fotografias que enquadravam a televisão transmitindo o debate eleitoral. Qual é o significado político dessas imagens? Essas imagens podem ser consideradas um meme político?

Com base nessas primeiras indagações, procuramos avaliar as fronteiras conceituais do que é um meme, e, subsequentemente, do que é um meme político, em tentativa de responder à Q1 (De que maneira é possível qualificar as imagens com fotos de aparelhos de televisão exibindo o debate eleitoral como um tipo de meme político?). A resposta à Q1 não é direta e imediata, mas pode ser perseguida se atentarmos aos dados comparativos com outros gêneros de memes. produto cultural. No enredo, os autores se apropriam de criações (personagens, cenários, etc.) de terceiros e desenvolvem universos paralelos à obra original. Filmes, séries, histórias em quadrinhos e outros gêneros de produções da cultura popular têm sido pródigos em gerar fanfics. 


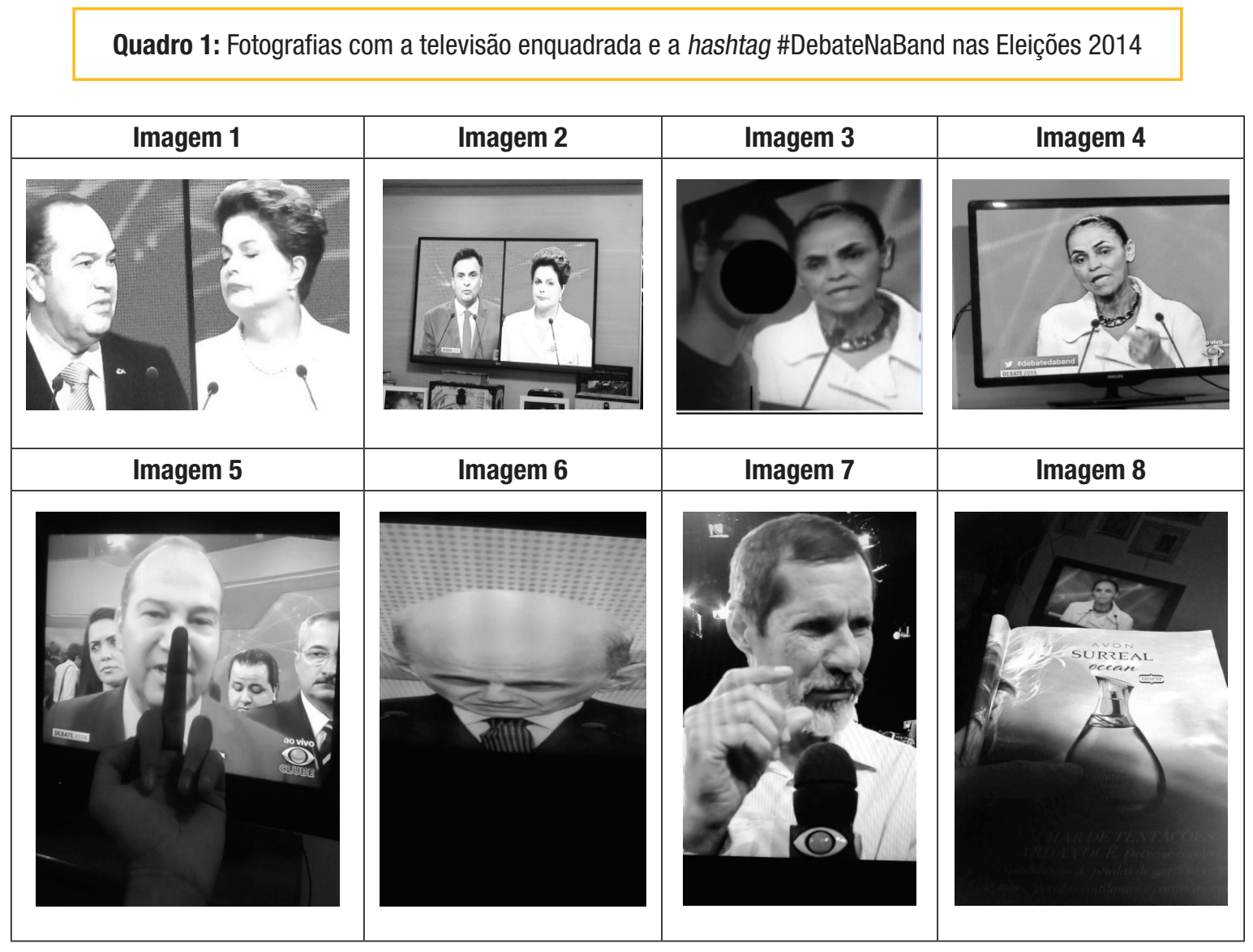

Fonte: Dataset de imagens cedido pelo grupo de pesquisa coLAB/UFF a partir de coleta realizada no Twitter.

Em primeiro lugar, cabe ressaltar que as

fotografias com a televisão enquadrada, em relação a outros gêneros, ocuparam lugar de destaque na paisagem iconográfica dos memes coletados durante os debates eleitorais. A comparação com selfies, por exemplo, é irrisória. De todas as 599 imagens, somente 3 eram selfies de eleitores, uma delas também com a televisão enquadrada, denotando apoio à candidata Marina Silva (Imagem 3). Ainda de acordo com estudo anterior (CHAGAS et al., 2017), dentre os gêneros mais conhecidos de memes, como os image macros (imagens com legenda sobreposta), os look-alikes (comparações entre dois personagens reais ou fictícios), e os exploitables (montagens com sobreposição de elementos), foram poucos os indícios de que a produção de um desses tipos de memes é dominante em relação aos demais. Os dados dão conta de que não mais do que $14,3 \%$ de macros $(\mathrm{N}=86), 9,5 \%$ de exploitables $(\mathrm{N}=57)$ e $1,7 \%$ de look-alikes $(\mathrm{N}=10)$ circularam entre as imagens do debate. Em relação aos 12,2\% de fotos de televisão $(\mathrm{N}=73)$, queremos crer que estamos diante de um fenômeno digno de observação. Como experiência compartilhada de comentário social, esses conteúdos contêm em si as características definidoras de um gênero de meme. 
Em relação ao conjunto das 73 imagens obtidas a partir da televisão, apenas 9,5\% $(\mathrm{N}=7)$ buscavam o humor através da própria imagem (cf. p.ex. Imagem 6), à parte as legendas provenientes dos tweets textuais. 0 humor, entretanto, não é distintivo sine qua non de um meme. Como recordam Shifman (2014), Milner (2013) e outros autores, não é o humor que caracteriza grande parte dos memes políticos que poderíamos classificar como de ação popular. Tais peças se destacam pela militância à medida que apresentam apelos dramáticos. 0 drama, como explica Bennett (1979, p. 344), geralmente é empregado como elemento do teatro político (cf. GOMES, 2004), e emerge seja de situações em que se constitui um conflito entre os atores e seus oponentes, ou de eventos que geram solidariedade em vista de uma identidade coletiva ou de um destino comum. Nesse sentido, o conjunto de fotos de televisão proporciona uma interdiscursividade dramática entre os atores, dando a conhecimento público de que estão todos assistindo ao debate. São conteúdos expressivos de uma "cidadania ativa", viabilizados por tecnologias digitais e com uma gramática particular, a qual "se ancora em um pathos para fomentar o engajamento" (MILNER, 2013, p. 2372). Mas seria possível compreender essas manifestações como um tipo de ação coletiva baseado na conversação informal na internet, conforme procuramos investigar com Q2?

Há um extenso debate na literatura sobre comunicação política a respeito do papel da conversação civil (MARQUES, 2006). Autores como Schudson (2009) são céticos em relação à percepção da conversação como eventual solução democrática. Eles argumentam que a intimidade, 0 senso de pertencimento e a constituição de uma comunidade em si mesma não são fatores que provenham qualquer termo aos problemas da democracia. Por outro lado, Maia (2012, p. 212) ressalta que, "Embora geralmente não estruturada, carente de propósito claro, e aparentemente trivial, a conversação entre os cidadãos é um meio de produzir e reproduzir a razão pública”. A pesquisadora reafirma o papel da conversa informal sobre política, indicando que não há necessariamente uma dicotomia entre a conversação e processos deliberativos, pelo contrário: importantes conexões entre as trocas informais e a razão pública podem ser percebidas a partir da produção de recursos para a formação da opinião. A conclusão legada por Maia (2012) é que conversas informais contribuem para tornar o processo político inteligível ao público. E esta inteligibilidade é, em grande medida, decorrente daquilo que, na visão de Weirich (2009, p. 4) - estreitamente relacionada com o desenvolvimento posterior da teoria da ação coletiva de Olson (op. cit.) -, pode ser encarado como o princípio mais fundamental da racionalidade coletiva, a consistência.

Milner (2013), por sua vez, empreende uma outra chave conceitual para explicar os memes surgidos durante o Occupy Wall Street: a ideia de que estas manifestações expressam uma polivocalidade popular (pop polyvocality). Nossa 
abordagem se alinha com a proposta por Milner. E, diferentemente do que afirma García (2015), ao sugerir que os memes são elaborados por um único indivíduo, mas refletem a opinião de um coletivo, a incidência de fotografias da televisão durante os debates eleitorais em 2014 deixa claro que só é possível perceber essas manifestações em seu conjunto. Isoladamente, à moda do que postula Shifman (2014), as imagens - mesmo em conjunto com seus respectivos tweets textuais - guardam um significado bastante mais restrito do que quando dispostas de modo adjacente, como um acervo. Assim, não é possível pensar separadamente as ações destes usuários, pois seu conjunto conforma a expressão da conversa informal na rede enquanto ação coletiva. São os internautas casuais (ALDÉ, 2011a) exibindo uns aos outros sua condição de participantes da cena política.

Nesse sentido, as fotografias de televisão apresentam, todas elas, uma expectativa dialógica em relação a outros usuários. As cenas apresentadas em imagens como as figuras 2 e 4 podem ser caracterizadas como uma tentativa de transmitir 0 interesse pela política. $0 \mathrm{~s}$ close-ups nas imagens (como na Imagem 1) são normalmente acompanhados de diálogos internos, parodísticos, tratando os políticos como personagens de uma fanfic desenvolvida pelo próprio sujeito.

Já as capturas de cenas descontextualizadas (Imagem 7, p.ex.) ou o recurso à distorção ou outras técnicas fotográficas (como na Imagem 6) servem ao propósito do humor situacional, isto é, da piada pela piada, muitas vezes até se despindo do contexto político original. Por fim, fotografias que apresentam intervenções diretas do sujeito em relação às imagens do debate (p.ex. Imagens 3, 5 e 8), embora mais raras, são as que melhor sustentam posicionamentos ideológicos ou morais, e, portanto, denotam um engajamento no seu sentido mais clássico.

As manifestações de opinião expressas por fotografias da televisão podem ser pensadas como "micro-doações de recursos" (cf. MARGETTS, 2013, p. 1) ao debate público, de maneira que a incidência de colaborações conforma univocamente 0 fenômeno. Desse modo, este conjunto de fotografias da televisão exibindo os debates eleitorais só pode ser compreendido como uma ação coletiva se e somente se tomado a partir da perspectiva da conversação informal na internet, fruto de um comportamento casual junto ao debate público, o que, por sua vez, já antecipa parcialmente as respostas à nossa terceira $\mathrm{e}$ última questão.

Vale ressaltar que este tipo de ação coletiva ocupa um lugar inteiramente diferente dos comportamentos evidenciados por Bennett \& Segerberg (2012): a ação coletiva, a ação coletiva híbrida e a ação conectiva. Em todos os casos, o comportamento casual é uma anomalia, posto que as ações coletivas se baseiam em um modelo teórico que compreende a cultura cívica 
como padrão normativo para 0 cidadão médio (GOLDFARB, 2012).

Diante disso, procuramos responder à Q3 (Qual é o posicionamento político predominante expresso pelos sujeitos que publicam este tipo de material?), investigando o vernáculo dos conteúdos coletados. Afinal, quem são os candidatos retratados? Quais são as manifestações e os posicionamentos desses eleitores?

A esse respeito, vale pontuar que, em 73,9\% ( $\mathrm{N}=51)$ dos conteúdos mapeados, um candidato apenas é representado, enquanto no restante, 0 recurso da tela dividida ao meio longitudinalmente, recém-introduzido nos debates televisivos, serviu para representar situações de dúvida do eleitorado ou de embates psicológicos fictícios, como o descrito na abertura deste capítulo. Com relação aos sujeitos apresentados nas imagens, as fotografias priorizaram as figuras de Dilma Rousseff e Marina Silva (Quadro 2), mas candidatos minoritários como Eduardo Jorge $(\mathrm{N}=11)$ e Levy Fidélix $(\mathrm{N}=10)$ despontaram logo na sequência, suplantando ou empatando com Aécio Neves $(\mathrm{N}=9)$. Algumas das imagens com Eduardo Jorge e Fidélix receberam comentários de chacota ou desaprovação no corpo do tweet; outras, como já advertimos, não continham qualquer posicionamento ideológico explícito.

Em cinco ocasiões apenas (7,2\%), eleitores manifestavam-se diante da televisão, seja erguendo o dedo médio em riste aos

candidatos ou utilizando-se de outro expediente - como o que abriu uma revista com a palavra "surreal" destacada, diante da televisão com a imagem de Marina Silva no debate (cf. Imagens 5 e 8). Nestes casos, é possível atribuir ao conteúdo iconográfico um posicionamento. Contudo, como pudemos perceber, esses casos são exceção à regra. A grande maioria das imagens simplesmente não permite qualquer avaliação de opinião. Com efeito, os resultados nesta seara são inconclusivos, exceto se pudéssemos conjugar à análise de conteúdo uma metodologia de análise de redes sociais (Social Network Analysis), reintegrando as imagens aos seus correspondentes tweets textuais e ampliando a escala de análise para 0 nível do que se reconhece como big data. Como, porém, a amostra sobre a qual nos debruçamos é reduzida e consiste basicamente de um acervo iconográfico retirado de contexto, os dados não foram suficientes para que pudéssemos auferir a posição dos sujeitos no espectro político. Ainda assim, o fato de as imagens cumprirem, na maior parte das vezes, a função de anunciar publicamente aos demais interlocutores a condição daquele sujeito como espectador do debate político televisivo expressa engajamento na linha do que demarcam Bimber, Flanagin \& Stohl (2012) isto é, de que o engajamento político deve ser visto como experiência em que os indivíduos 
participam do processo de constituição da agenda pública.

\section{Considerações finais}

0 presente trabalho buscou reforçar a discussão sobre as reconfigurações do papel da comunicação política em vista das novas formas de engajamento geradas pelo cenário de mudança tecnológica ora atravessado. Em especial, chamando a atenção para os estudos recentes sobre teoria da ação coletiva e relacionando-os às discussões de uma série de pesquisadores sobre o fenômeno dos memes de internet e seu entrelaçamento com o cenário de ativismo político contemporâneo, buscamos investigar dinâmicas de participação envolvidas na produção de conteúdo gerado por usuários no Twitter durante os debates presidenciais televisionados em 2014, quando um conjunto expressivo de usuários publicou fotografias do momento mesmo em que assistiam aos candidatos na televisão.

Anteriormente, classificamos estes conteúdos segundo uma taxonomia proposta por Chagas et al. (2017) como memes de ação conectiva de engajamento relativo. 0s resultados desta etapa do trabalho nos permitem avançar no debate sobre este tipo de ação política, na medida em que não apenas relativizam de forma consistente 0 que a literatura concebe como um engajamento cívico - sobretudo, quando justapomos a abordagem da teoria da ação coletiva à discussão sobre manifestações pessoais e narcisísticas na política atual -, como também apontam características relacionadas a novos modos de expressão política e produção de sentido associados à conversação informal e às novas formas de circulação da opinião, notadamente através dos memes políticos.

\section{Referências}

AGGIO, Camilo. Os candidatos ainda evitam a interação? Twitter, comunicação horizontal e eleições brasileiras. E-Compós, 18 (1), 2015.

ALDÉ, Alessandra. A construção da política: democracia, cidadania e meios de comunicação de massa. Rio de Janeiro: Editora FGV, 2004.

. 0 internauta casual: notas sobre a circulação da opinião política na internet. In: Revista USP, 90, 2011a.

. Cidadãos da Rede. In: Contemporânea

(Uerj), 9 (3), $2011 \mathrm{~b}$.

; SANTOS, João Guilherme Bastos dos.

Petições Públicas e batalhas digitais. In: XXI COMPóS, Juiz de Fora (MG), 2012.

BENNETT, W. Lance. When politics becomes play. In:

Political behavor, 1 (4), 1979.

BENNETT, W. Lance; TOFT, Moshaum. Identity, technology, and narratives: transnational activism and social networks. In: CHADWICK, Andrew; HOWARD, Philip N. (org.) The Routledge Handbook of Internet Politics. New York: Routledge, 2010.

BENNETT, W. Lance; SEGERBERG, Alexandra.

The logic of connective action. In: Information,

Communication \& Society, 15 (5), 2012.

BIMBER, Bruce; FLANAGIN, Andrew J; STOHL, Cynthia. Collective action in organizations: interaction and engagement in an Era of Technological Change. Cambridge: Cambridge University Press, 2012. 
BÖRZSEI, Linda Kata. Political culture on the National Web: the role of political culture in online political activity and the case of Hungarian politics on Facebook. Utretch University, 2013. (Dissertação de Mestrado.)

BRUNDIDGE Jennifer; RICE Ronald. Political engagement online: do the information rich get richer and the like-minded more similar? In: CHADWICK, Andrew; HOWARD, Philip N. (org.) The Routledge Handbook of Internet Politics. New York: Routledge, 2010.

CERVI, Emerson U; MASSUCHIN, Michele G; CARVALHO, Fernanda C de (orgs.) Internet e Eleições no Brasil. Curitiba: CPOP, 2016.

CHAGAS, Viktor; FREIRE, Fernanda; RIOS, Daniel; MAGALHÃES, Dandara. A política dos memes e os memes da política: proposta metodológica de análise de conteúdo de memes dos debates eleitorais de 2014. In: Intexto, 38, 2017.

CHAGAS, Viktor; TOTH, Janderson Pereira.

Monitorando memes em mídias sociais. In: SILVA, Tarcízio; STABILE, Max (orgs.) Monitoramento e pesquisa em mídias sociais: metodologias, aplicações e inovações. São Paulo: Uva Limão, 2016.

DAWKINS, Richard. The selfish gene. New York: Oxford University Press, 1976.

FIGUEIREDO M.; ALDÉ A., DIAS, H.; JORGE, V. L. Estratégias de persuasão em eleições majoritárias: uma proposta metodológica para o estudo da propaganda política. In: Série Estudos (Iuperj), 100, 1998.

GAINOUS, Jason; WAGNER, Kevin M. Tweeting to power: the social media revolution in American politics. Nova Iorque: OUP, 2014.

GARCÍA, Ignacio Gómez. Los imemes como vehículos para la opinión pública. In: Versión Estudios de Comunicación Y Política, 35, 2015.

GERLACH, Luther. The structure of social movements: environmental activism and its opponents. In: ARQUILLA, John, RONFELDT, David. Networks and netwars: the future of terror, crime, and militancy. Santa Monica: Rand, 2001.

GOLDFARB, Jeffrey. Reinventing political culture: the power of culture versus the culture of power. Londres: Polity Press, 2012.

GOMES, Wilson. Transformações da política na era da comunicação de massa. São Paulo: Paulus, 2004.

HERRERA, José Ivanhoe Vélez. Influyendo en el ciberespacio con humor: imemes y otros fenómenos. In: Versión Estudios de Comunicación Y Política, 35, 2015.

KNOKE, David. Networks of political action: toward theory construction. In: Social Forces, 68 (4), 1990. LATTMAN-WELTMAN, Fernando. Democracia e revolução tecnológica em tempos de cólera: influência política e midiática e radicalização militante. In: VI Compolítica, Rio de Janeiro (RJ), 2015.

MAIA, Rousiley. Deliberation, the media and political talk. New York: Hampton Press, 2012.

MARGETTS, Helen; JOHN, Peter; HALE, Scott; REISSFELDER, Stéphane. Leadership without leaders? Starters and followers in online collective action. In: Political Studies, 2013.

MARQUES, Francisco Paulo Jamil Almeida. Debates politicos na internet: a perspectiva da conversação civil. In: Opinião Pública, 12 (1), 2006.

MILNER, Ryan. Pop polyvocality: internet memes, public participation, and the Occupy Wall Street Movement. In: International Journal of Communication, 7, 2013.

OLSON, Mancur. A lógica da ação coletiva. São Paulo: Edusp, 1999.

PAPACHARISSI. Zizi. A private sphere: democracy in a Digital Age. Cambridge: Polity Press, 2010. 
SANGLARD, Fernanda Nalon; SANTOS, João

Guilherme Bastos dos. A ação coletiva muito além das organizações. In: Revista Compolítica, 3 (1), 2013.

SANTINI, Rose Marie; REZENDE, Rafael; SILVA, Danilo; TERRA, Camyla; TRAIANO, Heloísa; SOARES, Kenzo; ORLANDIS, Marcela; BRASIL, Tulio; RESCALA, Clara. 0 'tipping point' dos protestos de Junho de 2013 no Brasil: uma análise do papel das velhas e das novas mídias na política hoje. In: VI Compolítica, Rio de Janeiro (RJ), 2015.

SCHUDSON, Michael. Why democracies need an unlovable press. Cambridge: Polity Press, 2009.

SHIFMAN, Limor. Memes in a Digital Culture. Cambridge: MIT Press, 2014.

STROMER-GALLEY, Jennifer. Interação on-line e por que os candidatos a evitam. In: MARQUES, Francisco Paulo Jamil Almeida; SAMPAIO, Rafael Cardoso; AGGIO, Camilo (org.). Do clique à urna: internet, redes sociais e eleições no Brasil. Salvador: Edufba, 2013.

TAY, Geniesa. Embracing LOLitics: popular culture, online political humor, and play. Christchurch: University of Canterbury, 2012. (Dissertação de Mestrado.)

VALENZUELA, Sebastián. Analisando o uso de redes sociais para o comportamento de protesto: 0 papel da informaçãa, da expressão de opiniões e do ativismo. In: Revista Compolítica, 4 (1), 2014.

WEIRICH, Paul. Collective rationality: equilibrium in cooperative games. New York: Oxford University Press, 2009. 
Revolution will be memetized: engagement and collective action in Brazilian 2014

\section{electoral debates memes}

\section{Abstract}

This article aims to develop a reflection on the relationship between political engagement, informal conversation and collective action through political play. The main goal is to understand a particular type of political information circulating in social media, the internet memes. Following up a broader research agenda, this paper analyzes a set of 73 images belonging to an original sample of 599 memes collected during the electoral debate broadcasted by Band TV in 2014. In common, all these images were published on Twitter and present photographs of a television that featured the debate. It is interesting to see to what extent it is possible (1) to qualify these images as political memes, (2) to characterize them as a collective action based on informal conversation, and (3) to identify the predominant political position expressed by them. In order to answer these questions, we undertake a content analysis in conjunction with a qualitative evaluation of these materials. The results point to the need to rethink the connection between civic engagement and political action from the perspective of casual citizen involvement with politics on the internet.

\section{Keywords}

Memes. Internet and politics. 2014 Elections.

Engagement.

\section{La revolución memetizada:}

el compromiso político y la acción colectiva en los imemes

\section{de los debates electorales}

\section{de 2014 en Brasil}

\section{Resumen}

Se propone en este artículo desarrollar una reflexión sobre la relación entre el engajamento político, la conversación informal y la acción colectiva sobre la brincadura política. El objetivo es conocer mejor un tipo de información política que circula en las redes sociales, los imemes. Seguindo a una agenda de investigaciones más amplias, este trabajo se propone analizar un conjunto de 73 imágenes de una muestra original de 599 memes colectados durante el debate electoral transmitido por la TV Band, en 2014. En común, todas las imágenes fueran publicadas en el Twitter y presentan fotografías de una televisión que exhibe el debate. Estamos interesados en percibir en qué medida es posible (1) calificar estas imágenes como imemes políticos, (2) caracterizá-las como una acción colectiva en una conversación informal, e (3) identificar cual es el posicionamiento político predominante expreso por ellas. Para dar cuenta de las cuestiones, llevamos a cabo una análisis de contenido conjugado a una evaluación cualitativa de materiales. Los resultados apuntan a una necesidad de repensar la conexión entre el compromiso cívico y el movimiento político a partir de la perspectiva de un compromiso casual con la política en Internet.

\section{Palabras clave}

Imemes. Internet y política. Elecciones 2014.

Compromiso político. 


\section{Expediente}

A revista E-Compós é a publicação científica em formato eletrônico da Associação Nacional dos Programas de Pós-Graduação em Comunicação (Compós). Lançada em 2004, tem como principal finalidade difundir a produção acadêmica de pesquisadores da área de Comunicação, inseridos em instituições do Brasil e do exterior.

\section{E-COMPÓS I www.e-compos.org.br I E-ISSN 1808-2599}

Revista da Associação Nacional dos Programas de Pós-Graduação em Comunicação.

Brasília, v.20, n.1, jan./abr. 2017.

A identificação das edições, a partir de 2008, passa a ser volume anual com três números.

Indexada por Latindex I www.latindex.unam.mx

\section{CONSELHO EDITORIAL}

Alda Cristina Silva da Costa, Universidade Federal do Pará, Brasil Alfredo Luiz Paes de Oliveira Suppia, Universidade Estadual de Campinas, Brasil Álvaro Larangeira, Universidade Tuiuti do Paraná, Brasil Ana Carolina D. Escosteguy, Pontifícia Universidade Católica do Rio Grande do Sul, Brasil Ana Regina Barros Rego Leal, Universidade Federal do Piauí, Brasil Ana Carolina Rocha Pessôa Temer, Universidade Federal de Goiás, Brasil Andrea França, Pontifícia Universidade Católica do Rio de Janeiro, Brasil André Luiz Martins Lemos, Universidade Federal da Bahia, Brasil Angela Cristina Salgueiro Marques, Faculdade Cásper Libero, Brasil Ângela Freire Prysthon, Universidade Federal de Pernambuco, Brasil Antonio Carlos Hohlfeldt, Pontifícia Universidade Católica do Rio Grande do Sul, Brasil Arthur Ituassu, Pontifícia Universidade Católica do Rio de Janeiro, Brasil Bruno Campanella, Universidade Federal Fluminense, Brasil Cláudio Novaes Pinto Coelho, Faculdade Cásper Líbero, Brasil Carlos Eduardo Franciscato, Universidade Federal de Sergipe, Brasil Denise Tavares da Silva, Universidade Federal Fluminense, Brasil Eduardo Vicente, Universidade de São Paulo, Brasil Eliza Bachega Casadei, Escola Superior de Propaganda e Marketing - SP, Brasil Elizabeth Nicolau Saad Corrêa, Universidade de São Paulo, Brasil Erick Felinto de Oliveira, Universidade do Estado do Rio de Janeiro, Brasil Erly Vieira Júnior, Universidade Federal do Espirito Santo, Brasil Francisco de Assis, FIAM-FAAM Centro Universitário, Brasil Francisco Elinaldo Teixeira, Universidade Estadual de Campinas, Brasil Frederico de Mello Brandão Tavares, Universidade Federal de Ouro Preto, Brasil Gabriela Reinaldo, Universidade Federal do Ceará, Brasil Gilson Vieira Monteiro, Universidade Federal do Amazonas, Brasil Gustavo Daudt Fischer, Universidade do Vale do Rio dos Sinos, Brasil Igor Sacramento, Fundação Oswaldo Cruz, Brasil Itania Maria Mota Gomes, Universidade Federal da Bahia, Brasil Jiani Adriana Bonin, Universidade do Vale do Rio dos Sinos, Brasil José Afonso da Silva Junior, Universidade Federal de Pernambuco, Brasil
José Luiz Aidar Prado, Pontifícia Universidade Católica de São Paulo, Brasil Juçara Gorski Brittes, Universidade Federal de Ouro Preto, Brasil Laura Loguercio Cánepa, Universidade Anhembi Morumbi, Brasil Liziane Soares Guazina, Universidade de Brasilia, Brasil Luíza Mônica Assis da Silva, Universidade Católica de Brasília, Brasil Maria Ataide Malcher, Universidade Federal do Pará, Brasil Maria Elisabete Antonioli, Escola Superior de Propaganda e Marketing - SP, Brasil Maria das Graças Pinto Coelho, Universidade Federal do Rio Grande do Norte, Brasil Marcel Vieira Barreto Silva, Universidade Federal da Paraíba, Brasil Marcia Tondato, Escola Superior de Propaganda e Marketing, Brasil Marli Santos, Universidade Metodista de São Paulo, Brasil Márcio Souza Gonçalves, Universidade do Estado do Rio de Janeiro, Brasil Mauricio Mario Monteiro, Universidade Anhembi Morumbi, Brasil Mauricio Ribeiro da Silva, Universidade Paulista, Brasil Mauro de Souza Ventura, Universidade Estadual Paulista, Brasil Mayka Castellano, Universidade Federal Fluminense, Brasil Micael Maiolino Herschmann, Universidade Federal do Rio de Janeiro, Brasil Mozahir Salomão Bruck, Pontifícia Universidade Católica de Minas Gerais, Brasil Nísia Martins Rosario, Universidade Federal do Rio Grande do Sul, Brasil Potiguara Mendes Silveira Jr, Universidade Federal de Juiz de Fora, Brasil Raquel Ritter Longhi, Universidade Federal de Santa Catarina, Brasil Regiane Regina Ribeiro, Universidade Federal do Paraná, Brasil Roberto Elísio dos Santos, Universidade Municipal de São Caetano do Sul, Brasil Rodolfo Rorato Londero, Universidade Estadual de Londrina, Brasil Sérgio Luiz Gadini, Universidade Estadual de Ponta Grossa, Brasil Simone Maria Andrade Pereira de Sá, Universidade Federal Fluminense, Brasil Simone Maria Rocha, Universidade Federal de Minas Gerais, Brasil Suzana Reck Miranda, Universidade Federal de São Carlos, Brasil Tarcyanie Cajueiro Santos, Universidade de Sorocaba, Brasil Tatiana Oliveira Siciliano, Pontifícia Universidade Católica do Rio de Janeiro, Brasil Veneza Mayora Ronsini, Universidade Federal de Santa Maria, Brasil

\section{CONSELHO CIENTÍFICO}

Cristiane Freitas Gutfreind, Pontifícia Universidade Católica do Rio Grande do Sul, Brasil Eduardo Morettin, Universidade de São Paulo, Brasil

Felipe Costa Trotta, Universidade Federal Fluminense, Brasil Irene de Araújo Machado, Universidade de São Paulo, Brasil

\section{COMISSÃO EDITORIAL}

Eduardo Antonio de Jesus, Universidade Federal de Minas Gerais, Brasil Marco Antonio Roxo da Silva, Universidade Federal Fluminense, Brasil Osmar Gonçalves dos Reis Filho, Universidade Federal do Ceará, Brasil

\section{CONSULTORES AD HOC}

Kelly C. de Souza Prudencio, Universidade Federal do Paraná, Brasil Francisco P. Jamil A. Marques, Universidade Federal do Paraná, Brasil Tiago Quiroga F. Neto, Universidade de Brasília, Brasil

\section{EQUIPE TÉCNICA}

ASSISTENTE EDITORIAL Márcio Zanetti Negrini REVISÃO DE TEXTOS Press Revisão EDITORAÇÃO ELETRÔNICA Roka Estúdio IMAGEM DE CAPA Silas de Paula

\section{COMPÓS I www.compos.org.br}

Associação Nacional dos Programas de Pós-Graduação em Comunicação

Presidente

Edson Fernando Dalmonte

Programa de Pós-Graduação em Comunicação

e Cultura Contemporânea - UFBA

edsondalmonte@uol.com.br

Vice-presidente

Cristiane Freitas Gutfreind

Programa de Pós-Graduação em Comunicação Social - PUC-RS cristianefreitas@pucrs.br

Secretário-Geral

Rogério Ferraraz

Programa de Pós-Graduação em Comunicação

Universidade Anhembi Morumbi

rogerioferraraz@anhembimorumbi.edu.br

CONTATO I revistaecompos@gmail.com 